\title{
Ectima gangrenoso en pacientes pediátricos hematooncológicos, infección oportunista. Revisión de casos clínicos en el Centro Médico Nacional 20 de Noviembre
}

\author{
Gangrenous ecthyma in pediatric hemato-oncologic patients, opportunistic \\ infection. Review of clinical cases in Centro Médico Nacional 20 de Noviembre
Esaú Luis Nieto,* Alfredo Morayta Ramírez Corona, ${ }^{\ddagger}$ Javier Ordoñez Ortega, ${ }^{\S}$ Jetzamín Gutiérrez Muñoz ${ }^{\dagger, \S}$
* Médico residente de Infectología Pediátrica.
₹ Jefe de Servicio de Infectología Pediátrica.
§ Médico adscrito al Servicio de Infectología Pediátrica.
Centro Médico Nacional 20 de Noviembre. Ciudad de México, México.

RESUMEN

El ectima gangrenoso es una infección rara de la piel, clásicamente asociada con Pseudomonas aeruginosa, otros agentes causales también han sido descritos como Streptococcus pyogenes, Staphylococcus aureus, Klebsiella pneumoniae, etcétera. En pacientes inmunocomprometidos con neutropenia, la mayoría de los casos son debido a Pseudomonas aeruginosa, planteando desafíos especialmente en el diagnóstico microbiológico y terapia antimicrobiana. El diagnóstico es eminentemente clínico, pero se debe confirmar mediante auxiliares diagnósticos (biopsia-cultivo, tinción Gram, examen histopatológico), lo cual es de suma importancia para iniciar un tratamiento antibiótico de manera temprana eficaz, ya que es un factor clave en el pronóstico para la supervivencia de los pacientes pediátricos. En este artículo realizamos la revisión retrospectiva de tres casos de ectima gangrenoso (EG) en pacientes inmunocomprometidos en un hospital de tercer nivel en la Ciudad de México.

Palabras clave: Infección de la piel y tejidos blandos, ectima gangrenoso, osteosarcoma condroblástico, leucemia linfoblástica aguda, infección por oportunistas.

\section{ABSTRACT}

Ecthyma gangrenosum is a rare skin infection, classically associated with Pseudomonas aeruginosa, other causative agents have also been described as Streptococcus pyogenes, Staphylococcus aureus, Klebsiella pneumoniae, etc. In immunocompromised patients with neutropenia, the majority of cases are due to Pseudomonas aeruginosa, posing challenges especially in microbiological diagnosis and antimicrobial therapy. The diagnosis is eminently clinical, but must be confirmed by other diagnostic methods (biopsy-culture, Gram stain, histopathological examination), being of utmost importance to start an effective early antibiotic treatment, since it is a key factor in the prognosis for survival of pediatric patients. In this article, we carry out a retrospective review of three clinical cases of ecthyma gangrenosum in immunocompromised patients at a third level hospital in Mexico City.

Keywords: Skin and soft tissue infection, ecthyma gangrenosum, chondroblastic osteosarcoma, acute lymphoblastic leukemia, opportunistic infection.

\footnotetext{
Citar como: Luis NE, Morayta RCA, Ordoñez OJ, Gutiérrez MJ. Ectima gangrenoso en pacientes pediátricos hematooncológicos, infección oportunista. Revisión de casos clínicos en el Centro Médico Nacional 20 de Noviembre. Rev Latin Infect Pediatr. 2021 ; 34 (3): 128-134. https://dx.doi.org/10.35366/102235
}

Recibido: 15-01-2021. Aceptado: 08-02-2021.

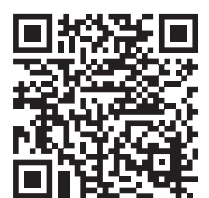


Rev Latin Infect Pediatr. 2021; 34 (3): 128-134

\section{INTRODUCCIÓN}

El ectima gangrenoso (EG) es una infección cutánea rara que puede estar acompañada o no de una bacteriemia sistémica y en algunos casos puede ser fatal. Esta patología fue descrita por el patólogo canadiense Dr. Lewellys Barker en 1897, asociado con sepsis por Pseudomonas aeruginosa; posteriormente denominado "ectima gangrenoso» por Hitschmann/Kreibich. ${ }^{1}$ EI EG es una infección profunda de la piel considerada potencialmente letal que se asocia en $74 \%$ de los casos a sepsis causada por Pseudomonas aeruginosa, se presenta con mayor frecuencia en brazos (área axilar), piernas, tronco, cara, región lumbosacra y área anogenital de pacientes inmunocomprometidos que cursan con aplasia secundaria a quimioterapia, infección por virus de inmunodeficiencia humana (VIH), neutropenia, mieloma múltiple, diabetes mellitus, agammaglobulinemia y pacientes con quemaduras extensas. ${ }^{2}$

Aunque el EG es poco frecuente, compromete el sistema microvascular de la dermis, progresa clínicamente de forma secuencial desde erupciones maculopapulares hasta ampollas o bulas hemorrágicas, posteriormente al denudarse forman ulceraciones necróticas con eritema circundante 0 halo eritematoso que, por lo general, no presentan una evolución clínica favorable en pacientes inmunocomprometidos. ${ }^{1,2}$

Como se mencionó previamente, $74 \%$ de los casos de EG están causados por Pseudomonas aeruginosa, otros agentes en menor porcentaje se han asociado con esta patología, entre ellos Streptococcus pyogenes, Staphylococcus aureus, Aeromonas hydrophila, Serratia marcescens, Aspergillus spp., Candida albicans, Escherichia coli, Corynebacterium diphtheriae, Neisseria gonorrhoeae, Yersinia pestis y virus del herpes simple. En general, el EG es causado por un solo agente infeccioso, excepcionalmente se han reportado casos con dos agentes causales. ${ }^{3-5} \mathrm{Se}$ reportan en este artículo tres casos clínicos de manera retrospectiva de EG diagnosticados en pacientes hematooncológicos pediátricos durante marzo de 2019 a febrero de 2020.

\section{CASOS CLÍNICOS}

\section{Caso clínico 1}

Paciente femenino de nueve años de edad, diagnóstico de osteosarcoma condroblástico en tibia izquierda. Acude al Servicio de Urgencias por fiebre de $39{ }^{\circ} \mathrm{C}$, escalofríos y dolor en región genital, se administró previamente ibuprofeno. A la exploración física se observó región genital con aumento de volumen y eritema en labios mayores, de predominio en el izquierdo, evolucionando a vesículas, coloración violácea y lesiones en sacabocado, con tamaño aproximado de $5 \times 4 \mathrm{~mm}$ con bordes definidos en ambos labios, la región perianal sin lesiones (Figura 1).

A su ingreso hospitalario se le realizó una toma de laboratorios con PCT $2.02 \mathrm{ng} / \mathrm{mL}$, PCR $126 \mathrm{mg} / \mathrm{L}$, leucocitos $660 \mathrm{cel} / \mathrm{mm}^{3}$, hemoglobina $8.6 \mathrm{~g} / \mathrm{dL}$, hematocrito $24.2 \%$, plaquetas 31,000 $\mathrm{cel} / \mathrm{mm}^{3}$, neutrófilos $70 \mathrm{cel} / \mathrm{mm}^{3}$, linfocitos 210 $\mathrm{cel} / \mathrm{mm}^{3}$, monocitos $360 \mathrm{cel} / \mathrm{mm}^{3}$, eosinófilos 20 $\mathrm{cel} / \mathrm{mm}^{3}$. Se realizó biopsia-cultivo e identificó mediante VITEK 2 XL (bioMérieux) Pseudomonas aeruginosa, con el siguiente patrón de sensibilidad, las concentraciones mínimas inhibitorias (MIC) fueron tomadas según el manual de Estándares de desempeño para las pruebas de susceptibilidad a los antimicrobianos, 29ª edición

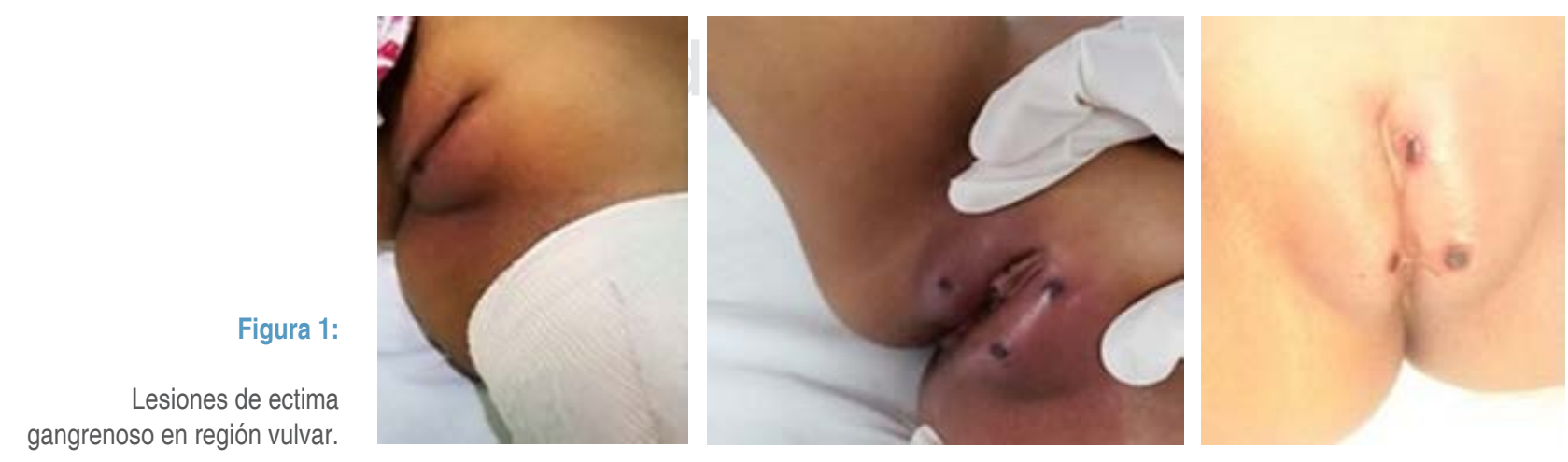


Figura 2:
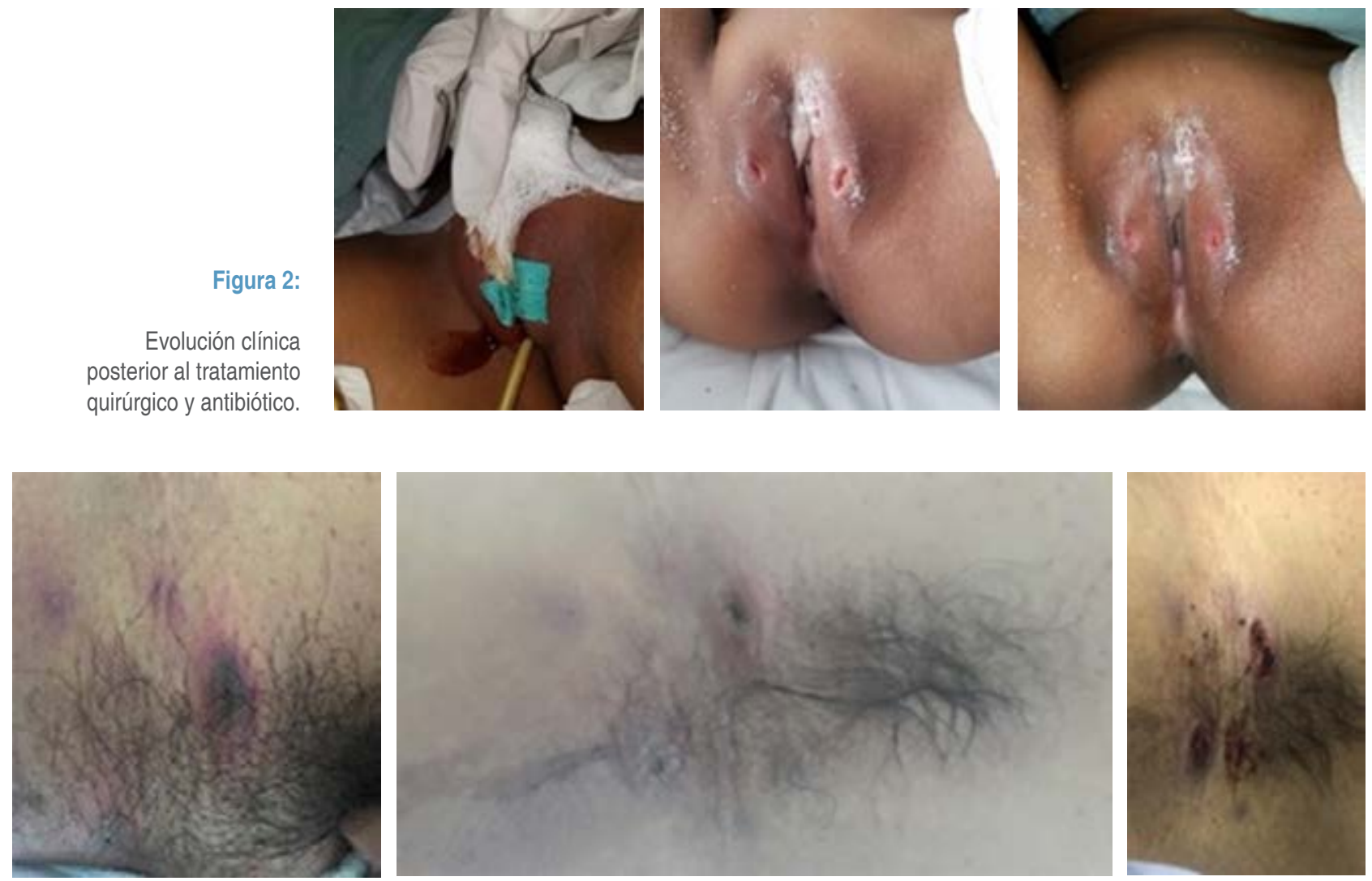

Figura 3: Datos clínicos de las lesiones axilares de ectima gangrenoso.

(CLSI 2019): piperacilina/tazobactam MIC $8 \mathrm{~S}$, cefepima MIC $2 \mathrm{~S}$, meropenem $\mathrm{MIC} \leq 0.25 \mathrm{~S}$, amikacina $\mathrm{MIC} \leq 2 \mathrm{~S}$, ciprofloxacino $\mathrm{MIC} \leq 0.25$ $S$, tigeciclina $M I C \geq 8 R$.

El tratamiento quirúrgico de la lesión genital consistió en la resección de puntos gangrenosos en su totalidad, con curetaje de los bordes y fondo de las tres lesiones. A su ingreso se inició manejo con cefepima a dosis de $150 \mathrm{mg} / \mathrm{kg} /$ día durante 14 días, basado en datos clínicos y control de estudios de laboratorio. Se observa evolución clínica favorable de manera paulatina, se toman nuevos estudios de laboratorio a los 10 días de tratamiento, los cuales se describen a continuación: PCT $0.11 \mathrm{ng} / \mathrm{mL}$, PCR $4.4 \mathrm{mg} / \mathrm{L}$, leucocitos $3,490 \mathrm{cel} / \mathrm{mm}^{3}$, hemoglobina $13.6 \mathrm{~g} / \mathrm{dL}$, hematocrito $39.5 \%$, plaquetas 294,000 $\mathrm{cel} / \mathrm{mm}^{3}$, neutrófilos $1,790 \mathrm{cel} / \mathrm{mm}^{3}$, linfocitos 930 $\mathrm{cel} / \mathrm{mm}^{3}$, monocitos $670 \mathrm{cel} / \mathrm{mm}^{3}$, eosinófilos $40 \mathrm{cel} /$ $\mathrm{mm}^{3}$ y basófilos $60 \mathrm{cel} / \mathrm{mm}^{3}$. Se egresa a domicilio por mejoría clínica, adecuada respuesta a tratamiento antibiótico y quirúrgico, sin complicaciones (Figura 2).

\section{Caso clínico 2}

Paciente masculino de 15 años de edad, con diagnóstico de leucemia linfoblástica aguda $B$ de alto riesgo. Acude por presencia de fiebre de 38-39.5 ${ }^{\circ} \mathrm{C}$ y dolor en región axilar derecha. A la exploración física presentó, en la región antes mencionada, lesiones aumentadas de volumen, con un tamaño aproximado de $1 \times 2 \mathrm{~cm}$ y de $1 \times 3 \mathrm{~cm}$, cambio de coloración violácea y bordes bien delimitados que evolucionaron a los tres días a lesiones en sacabocado con un fondo de aspecto necrótico (Figura 3).

Sus estudios de laboratorio a su ingreso reportan, previo a la cirugía, PCT $1.0 \mathrm{ng} / \mathrm{mL}$, PCR $45.9 \mathrm{mg} / \mathrm{L}$, leucocitos $590 \mathrm{cel} / \mathrm{mm}^{3}$, hemoglobina $8.8 \mathrm{~g} / \mathrm{dL}$, hematocrito $25.1 \%$, plaquetas $19,000 \mathrm{cel} / \mathrm{mm}^{3}$, neutrófilos $100 \mathrm{cel} / \mathrm{mm}^{3}$, linfocitos $450 \mathrm{cel} / \mathrm{mm}^{3}$, monocitos 40 $\mathrm{cel} / \mathrm{mm}^{3}$. La biopsia-cultivo identificó mediante VITEK 2 XL (bioMérieux) Pseudomonas aeruginosa, con el siguiente patrón de sensibilidad, las MIC fueron tomadas según el manual de Estándares de desempeño para las pruebas de susceptibilidad a los anti- 
microbianos, 29a edición (CLSI 2019): piperacilina/ tazobactam MIC 8 S, cefepima MIC 2 S, meropenem MIC $1 \mathrm{~S}$, amikacina MIC $<2 \mathrm{~S}$, ciprofloxacino MIC $<$ $0.25 \mathrm{~S}$, tigeciclina MIC $>8 \mathrm{R}$.

El tratamiento quirúrgico de las lesiones consistió en resección del tejido gangrenoso en su totalidad, con curetaje de bordes y fondo en ambas lesiones. Con base en datos clínicos y laboratorio se inició tratamiento con cefepima a dosis de $150 \mathrm{mg} / \mathrm{kg} /$ día durante 14 días y vancomicina $40 \mathrm{mg} / \mathrm{kg} /$ día durante seis días. Se realiza control de laboratorios después del inicio del tratamiento farmacológico con resultados de PCT $1.56 \mathrm{ng} / \mathrm{mL}$, PCR 101 $\mathrm{mg} / \mathrm{L}$, leucocitos $610 \mathrm{cel} / \mathrm{mm}^{3}$, hemoglobina $8.7 \mathrm{~g} /$ $\mathrm{dL}$, hematocrito $25.1 \%$, plaquetas $32,000 \mathrm{cel} / \mathrm{mm}^{3}$, neutrófilos $140 \mathrm{cel} / \mathrm{mm}^{3}$, linfocitos $410 \mathrm{cel} / \mathrm{mm}^{3}$, monocitos $20 \mathrm{cel} / \mathrm{mm}^{3}$. Cursa con adecuada evolución clínica progresivamente y se realizó control de estudios a los 11 días de tratamiento, con los siguientes resultados: PCT $<0.05 \mathrm{ng} / \mathrm{mL}, \mathrm{PCR}$ $0.5 \mathrm{mg} / \mathrm{L}$, leucocitos $1,610 \mathrm{cel} / \mathrm{mm}^{3}$, hemoglobina
$9.2 \mathrm{~g} / \mathrm{dL}$, hematocrito $27.5 \%$, plaquetas 115,000 $\mathrm{cel} / \mathrm{mm}^{3}$, neutrófilos $640 \mathrm{cel} / \mathrm{mm}^{3}$, linfocitos 890 $\mathrm{cel} / \mathrm{mm}^{3}$, monocitos $70 \mathrm{cel} / \mathrm{mm}^{3}$. Posteriormente se egresa del Servicio de Infectología Pediátrica, con remisión de síntomas y cuadro clínico, sin complicaciones (Figura 4).

\section{Caso clínico 3}

Paciente femenino de siete años de edad, con diagnóstico de leucemia linfoblástica aguda estirpe $B$ de alto riesgo, por falla a la inducción y consolidación. Acude al Servicio de Urgencias por presencia de fiebre de $38.3^{\circ} \mathrm{C}$ con escalofríos, se inicia manejo con cefepima por fiebre y sospecha de infección relacionada con catéter venoso central con aislamiento en hemocultivo central y periférico de Staphylococcus epidermidis.

A su ingreso hospitalario se tomaron estudios de laboratorio con PCT $0.09 \mathrm{ng} / \mathrm{mL}$, leucocitos $480 \mathrm{cel} / \mathrm{mm}^{3}$, hemoglobina $9.6 \mathrm{~g} / \mathrm{dL}$, hematocrito
Figura 4:

Evolución clínica de las mismas lesiones posterior al tratamiento quirúrgico y antibiótico.
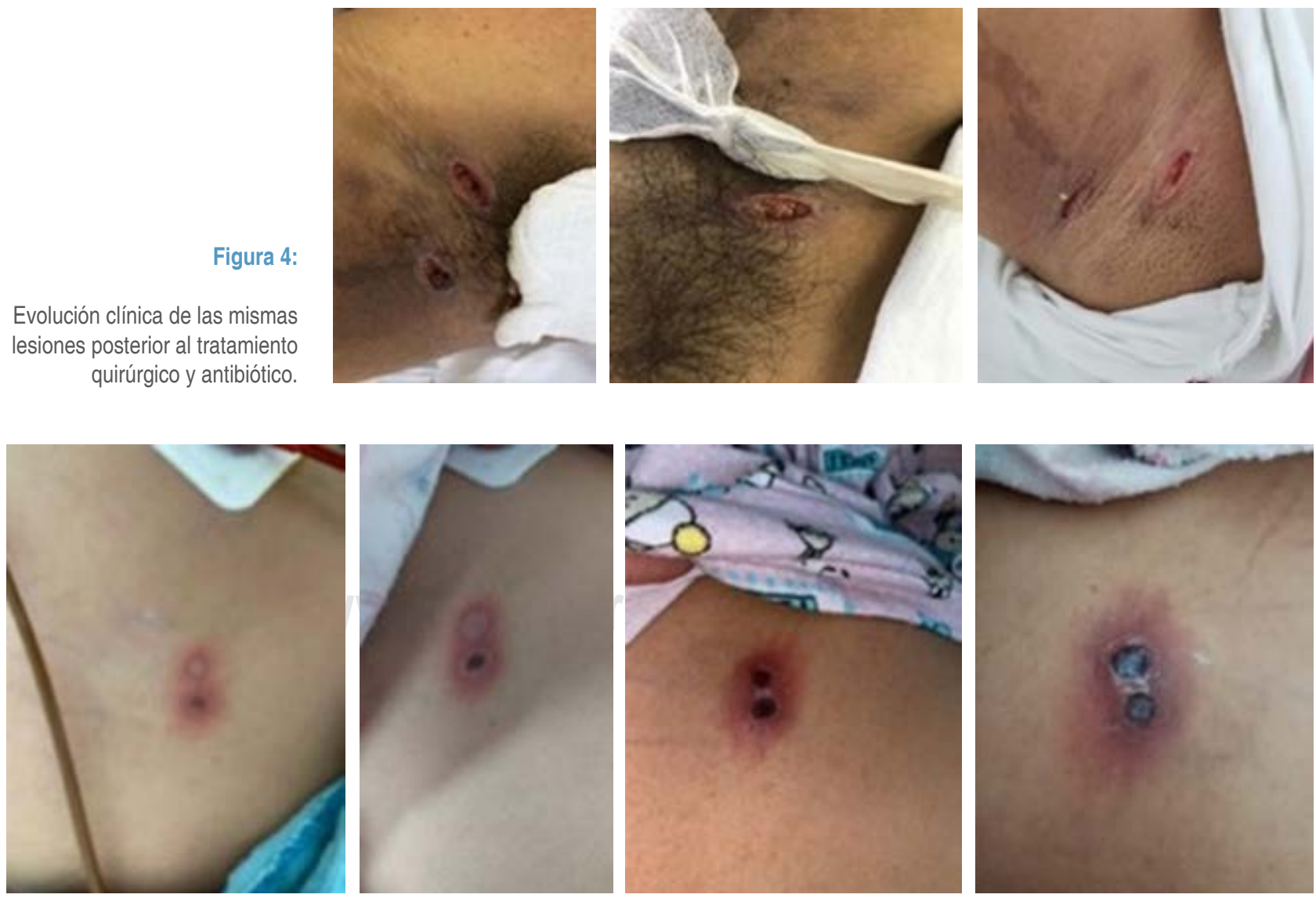

Figura 5: Datos clínicos de las lesiones en región de borde costal izquierdo de ectima gangrenoso. 


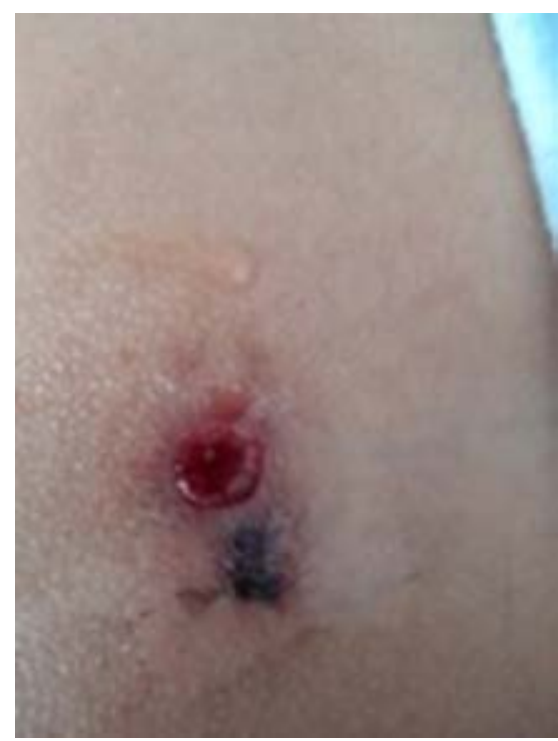

Figura 6: Evolución clínica de las lesiones después del tratamiento quirúrgico y antibiótico.

$28.9 \%$, plaquetas $6,000 \mathrm{cel} / \mathrm{mm}^{3}$, neutrófilos 20 $\mathrm{cel} / \mathrm{mm}^{3}$, linfocitos $460 \mathrm{cel} / \mathrm{mm}^{3}$, monocitos 00 $\mathrm{cel} / \mathrm{mm}^{3}$.

Posteriormente presenta dolor abdominal a los 10 días de evolución, por lo que se realizó un ultrasonido abdominal con máximo grosor colónico de $6.8 \mathrm{~mm}$ realizando diagnóstico de colitis neutropénica, por lo que se inicia manejo con piperacilina/tazobactam, presenta mala evolución con datos de irritación peritoneal y abdomen agudo, se decide valoración por cirugía pediátrica, quienes realizan laparotomía exploratoria (LAPE), encontrando como hallazgo apendicitis perforada, se realiza cambio de antibiótico a meropenem. A los 10 días de estancia intrahospitalaria, a la exploración física se observó dos lesiones a nivel de borde costal izquierdo, con halo eritematoso, formación de vesícula, evolucionando a coloración violácea y posteriormente lesiones en sacabocado con fondo necrótico y costras melicéricas, con tamaño aproximado de $1 \times 1 \mathrm{~cm}$, con bordes definidos de forma circular (Figura 5).

Se realizó control de laboratorios con la sospecha diagnóstica de EG con PCT $0.52 \mathrm{ng} / \mathrm{mL}$, leucocitos $630 \mathrm{cel} / \mathrm{mm}^{3}$, hemoglobina $15.3 \mathrm{~g} / \mathrm{dL}$, hematocrito $46.2 \%$, plaquetas $71,000 \mathrm{cel} / \mathrm{mm}^{3}$, neutrófilos $10 \mathrm{cel} /$ $\mathrm{mm}^{3}$, linfocitos $590 \mathrm{cel} / \mathrm{mm}^{3}$, monocitos $30 \mathrm{cel} / \mathrm{mm}^{3}$.

Se realizó resección de una lesión gangrenosa en su totalidad, con toma de biopsia-cultivo, curetaje de bordes y fondo de lesión. Se continuó manejo con meropenem a dosis $60 \mathrm{mg} / \mathrm{kg} /$ día y vancomicina a dosis $40 \mathrm{mg} / \mathrm{kg} /$ día durante 21 días totales, debido a que no se aisló el agente etiológico en la biopsiacultivo.

Presentó una evolución clínica favorable y se realizan estudios de gabinete de control al finalizar antibiótico: PCT $0.09 \mathrm{ng} / \mathrm{mL}$, leucocitos $1,960 \mathrm{cel} /$ $\mathrm{mm}^{3}$, hemoglobina $9.5 \mathrm{~g} / \mathrm{dL}$, hematocrito $28.5 \%$, plaquetas $7,000 \mathrm{cel} / \mathrm{mm}^{3}$, neutrófilos $310 \mathrm{cel} / \mathrm{mm}^{3}$, linfocitos $1,590 \mathrm{cel} / \mathrm{mm}^{3}$, monocitos $20 \mathrm{cel} / \mathrm{mm}^{3}$, eosinófilos $20 \mathrm{cel} / \mathrm{mm}^{3}$. Posteriormente, se egresa del Servicio de Infectología Pediátrica sin manejo antibiótico, por adecuada evolución clínica y remisión de diagnósticos, sin complicaciones (Figura 6).

\section{DISCUSIÓN}

El ectima gangrenoso es una entidad rara, bien conocida, que se puede deber a una infección por Pseudomonas aeruginosa, esta entidad se puede presentar con o sin sepsis. Se ha identificado a esta bacteria como parte de los patógenos frecuentes de enfermedades asociadas con cuidados de la salud, por su adaptación al medio hospitalario, debido a sus bajos requerimientos nutricionales y tolerancia a gran variedad de condiciones físicas, además de haber desarrollado una gran resistencia intrínseca a un gran número de antibióticos de amplio espectro. $2,4,6$

La etiología, como se ha mencionado de manera reiterativa, es por Pseudomonas aeruginosa en $73.65 \%$, otras bacterias $(17.35 \%)$ y hongos (9\%). $Y$ de los casos identificados con Pseudomonas aeruginosa se describió sepsis en $58.5 \%$, mientras que en $41.5 \%$ no hubo asociación con septicemia. ${ }^{7}$

Los principales factores de riesgo son neutropenia secundaria a quimioterapia, en patologías oncológicas hematológicas, hipogammaglobulinemia o agammaglobulinemia, anemia aplásica, trasplante de órgano sólido y síndrome de inmunodeficiencia adquirida (SIDA). La neutropenia persistente en estos pacientes, además de ser factor de riesgo, es de mal pronóstico, incluso en casos en los que no tienen bacteriemia. ${ }^{8-10}$

En la fisiopatogenia el EG se separa en dos formas clínicas (séptico y no séptico). El EG séptico es más común, en el cual el agente etiológico se propaga por vía hematógena a los capilares e invaden la adventicia y capa media de las arterias y venas. La invasión perivascular conduce a necrosis isquémica de la piel circundante (vasculitis necrosante). En la forma no 
Rev Latin Infect Pediatr. 2021; 34 (3): 128-134

bacteriana, las lesiones se presentan en el sitio donde hubo una inoculación directa en la epidermis. Las toxinas y enzimas de virulencia producidas por $P$. aeruginosa (exotoxina $\mathrm{A}$, elastasa y fosfolipasa $\mathrm{C}$ ) causan destrucción cutánea y vascular, además de que evitan una migración adecuada de granulocitos. . $^{2,4,6}$

El tratamiento empírico de elección es un betalactámico antipseudomónico, como cefalosporinas de tercera generación, cuarta generación, carbapenémicos y penicilinas de amplio espectro, e incluso está descrito el uso de aminoglucósidos. De manera adicional, se deben tomar en cuenta los aislamientos hospitalarios y los patrones de resistencia para iniciar un manejo empírico. Al identificar el microorganismo, se debe revisar su perfil de susceptibilidad para dirigir la terapia antibiótica. ${ }^{11,12}$

Un reporte de ocho casos de EG realizado en el año 2017 en el Hospital Universitario de la Universidad de Nuevo León ${ }^{13}$ coincide con Todd y sus colaboradores ${ }^{14}$ al indicar que el factor más común para esta entidad infecciosa es la neutropenia en pacientes inmunocomprometidos. También concluyeron que en el caso de pacientes pediátricos sanos y diagnosticados con EG es sumamente necesaria la evaluación inmunológica para descartar una posible inmunodeficiencia subyacente. De la misma forma, apuntaron a que un tratamiento antibiótico de amplio espectro es imprescindible para aumentar la supervivencia de los pacientes. Entre los antibióticos que reportaron con una evolución favorable fueron el imipenem y las combinaciones de ceftazidima + amikacina, meropenem + amikacina y un caso manejado con meropenem + ciprofloxacino.

Bodey, en su estudio de 410 episodios de bacteriemia de Pseudomonas aeruginosa en pacientes hematooncológicos, en un periodo de 10 años, encontró que la tasa global de curación fue de $62 \%$; para los pacientes con tratamiento adecuado fue de $67 \%$, mientras que en los pacientes con tratamiento antibiótico inadecuado fue de 14\%. En los pacientes con retraso en el tratamiento antibiótico de 24 a 48 horas se redujo la tasa de curación de 74 a $46 \%$. Otro dato importante en el tratamiento antibiótico fue que se encontró la diferencia de pacientes que recibieron betalactámico antipseudomónico con o sin aminoglucósido con mayor tasa de curación contra los que sólo recibieron tratamiento con aminoglucósido, con tasa de curación de 72 y $71 \%$ contra el $29 \%$, respectivamente. ${ }^{15}$

La tasa de mortalidad general se encuentra reportada en esta patología hasta en $41.6 \%$, se describe que hasta en $90 \%$ de los casos finados tuvo influencia el tratamiento antibiótico que se otorgó de manera tardía. ${ }^{16}$ Los pacientes con EG septicémico se asocia con mal pronóstico y mortalidad de 20 a $77 \%$; en cambio, los pacientes con EG no séptico la tasa de mortalidad se reportó menor entre 8 y $15 \%{ }^{1}$

En los casos antes descritos, los tres pacientes presentaron un diagnóstico de base hematooncológico y recibieron quimioterapia previa a su ingreso, a su arribo a la sala de urgencias se corroboró la presencia de neutropenia en todos ellos. En un caso ya se presentaban las lesiones de ectima a su ingreso y en los dos casos siguientes se observaron las lesiones a los tres y 10 días de estancia hospitalaria, respectivamente. Por lo cual, se realizó en primera instancia el abordaje diagnóstico basado en el cuadro clínico, además de los factores de riesgo asociados, de esta manera se inició el tratamiento antibiótico empírico temprano, con cefalosporina de cuarta generación y completando el abordaje diagnóstico con exéresis y biopsia-cultivo de las lesiones, aislándose en dos de los casos Pseudomonas aeruginosa, en el tercer caso no se logró tener aislamiento microbiológico; se inició tratamiento con cefepima, obteniendo resultados favorables y en el último caso recibió tratamiento con meropenem remitiendo las lesiones de manera exitosa. En esta serie de casos concordamos con lo reportado en la literatura donde el principal agente etiológico causal es $P$. aeruginosa, y en cuanto a los factores de riesgo de los pacientes, como se reporta en la literatura, los cánceres hematológicos acompañados de neutropenia profunda y prolongada son algunos de los más frecuentes asociados a esta patología.

Los tres casos presentados corresponden a la variedad septicémica de la enfermedad, siendo la clave del éxito del tratamiento la toma de cultivos, el inicio de tratamiento temprano y agresivo de antibiótico, así como el ajuste del esquema antimicrobiano en caso de presentar resistencia al mismo. El tratamiento quirúrgico que frecuentemente consiste en la escisión de las lesiones necróticas o drenaje de abscesos es de suma importancia para lograr el control efectivo de la fuente de infección, por lo que debe ir de la mano con el tratamiento médico.

\section{CONCLUSIÓN}

El ectima gangrenoso, si bien es una entidad poco frecuente, debe ser sospechada en los pacientes con los factores de riesgo previamente mencionados, que 
presenten un cuadro febril asociado con lesiones de piel inicialmente violáceas o maculopapulares sumamente dolorosas, que evolucionan rápidamente a ulceraciones necróticas, por lo que un examen físico minucioso es necesario para sospechar y reconocer esta entidad. El inicio temprano de betalactámicos antipseudomónicos hace la diferencia entre un buen y mal pronóstico.

\section{REFERENCIAS}

1. Shah M, Crane JS. Ecthyma gangrenosum. In: StatPearls [Internet]. Treasure Island (FL): StatPearls Publishing; 2021. Available from: https://www.ncbi.nlm.nih.gov/books/ NBK534777/

2. Abdou A, Hassam B. Ecthyma gangrenosum. Pan Afr Med J [Internet]. 2018; 30: 95. Available from: https://pubmed.ncbi. nlm.nih.gov/30344879/

3. Fuentes MDA. Ectima gangrenoso en un paciente pediátrico. Acta Med. 2020; 18 (1): 100-101.

4. Birlutiu V, Birlutiu RM, Baicu M, Iancu GM. A case report of double etiology of ecthyma gangrenosum: Pseudomonas aeruginosa and Enterococcus faecalis in an immunocompromised child occurred during influenza evolution. Medicine (Baltimore). 2019; 98 (20): e15651.

5. García RA, Vaquera ADN, Rosales SGM, Mascareñas SAH, De la O Cavazos M. Ectima gangrenoso por Pseudomonas aeruginosa en un paciente prematuro. Rev Latin Infect Pediatr [Internet]. 2019; 32 (1): 27-30. Disponible en: https:// www.medigraphic.com/pdfs/infectologia/lip-2019/lip191f.pdf

6. Yassaee KM, James DW. Ecthyma Gangrenosum. Medscape. 2020. Available from: https://emedicine. medscape.com/article/1053997-overview

7. Vaiman M, Lazarovitch T, Heller L, Lotan G. Ecthyma gangrenosum and ecthyma-like lesions: review article. Eur J Clin Microbiol Infect Dis. 2015; 34 (4): 633-639.

8. Vergara E, Largo J, Galván F. Ectima gangrenoso en niño sano sin septicemia. Colomb Med. 2007; 38 (4): 408-411.

9. Bucak IH, Tumgor G, Mengen E, Temiz F, Turgut M. Ecthyma gangrenosum in a previously healthy pediatric patient and associated facial paralysis and persistent hyperplastic primary vitreous. Am J Case Rep. 2012; 13: 250-253. Available from: https://doi.org/10.12659/ AJCR.883503

10. Zomorrodi A, Wald ER. Ecthyma gangrenosum: considerations in a previously healthy child. Pediatr Infect Dis J. 2002; 21 (12): 1161-1164.

11. Levinson W. Bacteriología clínica. Bacilos Gram negativos asociados al tracto gastrointestinal. Microbiología e inmunología médica. 8aㅡ edición. McGraw Hill; 2004.

12. Hatzenbuehler J, Pulling TJ. Diagnosis and management of osteomyelitis. Am Fam Physician. 2011; 84 (9): 1027-1033.

13. Martínez-Longoria CA, Rosales-Solis GM, Ocampo-Garza J, Guerrero-González GA, Ocampo-Candiani J. Ecthyma gangrenosum: a report of eight cases. An Bras Dermatol [Internet]. 2017; 92 (5): 698-700. Available from: https:// pubmed.ncbi.nlm.nih.gov/29166510/\#affiliation-1

14. Todd N, Boucher JE, Bassal M, Dumont T, Fleming N. Ecthyma gangrenosum: vulvar ulcers, pseudomonas, and pancytopenia: a case report of an 18-month-old female toddler. J Pediatr Adolesc Gynecol. 2018; 31 (6): 625-628.

15. Bodey GP, Jadeja L, Elting L. Pseudomonas bacteremia. Retrospective analysis of 410 episodes. Arch Intern Med. 1985; 145 (9): 1621-1629.

16. Biscaye S, Demonchy D, Afanetti M, Dupont A, Haas H, Tran A. Ecthyma gangrenosum, a skin manifestation of Pseudomonas aeruginosa sepsis in a previously healthy child: a case report. Medicine (Baltimore). 2017; 96 (2): e5507.

Financiamiento: Ninguno.

Conflicto de intereses: Ninguno.

Correspondencia:

Esaú Luis Nieto

Centro Médico Nacional 20 de Noviembre.

Félix Cuevas Núm. 540,

Col. Del Valle Sur, 03200,

Alcaldía Benito Juárez, Ciudad de México.

E-mail: dresauln@gmail.com 